\title{
ROUTINE EPISIOTOMY CAUSES MORE MORBIDITY IN PAROUS WOMEN, A CASE CONTROLLED STUDY CONDUCTED IN KANNUR MEDICAL COLLEGE
}

\author{
Keloth Manapatt Asokan', Smitha Santhosh ${ }^{2}$
}

${ }_{1}^{1}$ Professor, Department of Obstetrics and Gynaecology, Kannur Medical College, Anjarakandy.

${ }^{2}$ Associate Professor, Department of Obstetrics and Gynaecology, Kannur Medical College, Anjarakandy.

ABSTRACT
AIM OF STUDY
Episiotomy is a surgical procedure done to assist delivery, which is widely practiced world over. This is a comparative study with
episiotomy and without episiotomy during vaginal delivery. The aim of the present study is to show routine episiotomy in the
multiparous ladies is not a boon but a bane.

\section{MATERIALS AND METHODS}

Samples are collected during from 2010 to 2014. Total 500 cases were selected for study purpose; 250 cases underwent episiotomy during second stage of labor and 250 cases without episiotomy.

\section{Inclusion Criteria}

Inclusion Criteria are parity equal to and more than two.

\section{Exclusion Criteria}

Exclusion criteria are risk factors like obstetric complications, medical complications and previous caesarean delivery.

\section{CONCLUSION}

Episiotomy in multiparous ladies causes more morbidity than in ladies without epi siotomy. Hospital stay also increased in episiotomy cases.

\section{KEYWORDS}

Episiotomy, Mediolateral Episiotomy, Midline Episiotomy, Nulliparous Woman, Multiparous Woman, 3을 Perineal Tear, 4은 Perineal Tear, Shoulder Dystocia and Dyspareunia.

HOW TO CITE THIS ARTICLE: Asokan KM, Santhosh S. Routine episiotomy causes more morbidity in parous women, a case controlled study conducted in Kannur Medical College. J. Evolution Med. Dent. Sci. 2016;5(18):902-904,

DOI: $10.14260 /$ jemds/2016/208

\section{INTRODUCTION}

Episiotomy is the incision made on the perineum to widen the introitus and straighten the birth canal. It is a type of $2^{-}$ perineal tear.[1] The first recorded procedure was done by Ould.[2] Two types of episiotomies are performed nowadays, median (Midline) and mediolateral [Figure 1]. Median or midline episiotomy is popular in the US and the mediolateral in India and most of the Asian countries. Episiotomy is routinely practiced in Latin America and India.[3] It is performed in certain strict indications like primi gravida, face-to-pubis delivery, shoulder dystocia, after-coming head delivery in breech presentation and delivery of premature fetuses. This type of episiotomy is known as restrictive episiotomy. The aim of episiotomy is to reduce the complicated perineal tears like $3^{\circ}$ or $4^{\circ}$ perineal tear.[4] Spontaneous tears are defined as:

- First Degree (Involving the fourchette, perineal skin and vaginal mucous membrane, but not the underlying fascia and muscle);

- Second Degree (Involving the perineal muscles and skin);

Financial or Other, Competing Interest: None.

Submission 18-01-2016, Peer Review 12-02-2016,

Acceptance 19-02-2016, Published 03-03-2016.

Corresponding Author:

Dr. Keloth Manapatt Asokan,

Department of Obstetrics and Gynaecology,

Anjarakandy-670612,

Kannur, Kerala.

E-mail:drkmasokan@gmail.com

DOI: $10.14260 /$ jemds $/ 2016 / 208$
- Third Degree (Injury to the anal sphincter complex: $3 a=$ $<50 \%$ of the external anal sphincter torn $3 b=50 \%$ of the external anal sphincter torn $3 c=$ Injury to the external and internal anal sphincter); and

- Fourth Degree (Injury to the perineum involving the anal sphincter complex and anal epithelium).[5]

Episiotomy was extensively done in the 70s and 80s in US. The reasons postulated were the episiotomy wound was easy to repair rather than repairing a ragged tear caused by tear by an unassisted delivery. It was also believed that postoperative pain was very less. Another benefit of episiotomy was that it prevented pelvic relaxation and prevents pelvic organ prolapse. Although episiotomy has become one of the most commonly performed surgical procedures in the world, it was introduced without strong scientific evidence of its.[6]

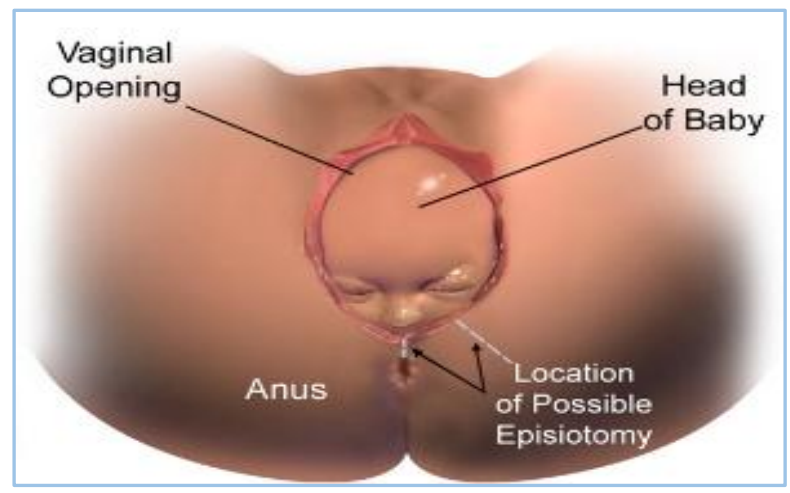

Fig. 1: Episiotomy Procedures 


\section{AIM OF STUDY}

This a comparative study to assess the complications of episiotomy on multiparous pregnant women.

\section{MATERIALS AND METHODS}

500 cases have been selected for study purpose between 2010 and 2014; 250 multiparous (Equal to and more than two previous vaginal birth) women have undergone right mediolateral episiotomy. Other 250 women were delivered without episiotomy.

\section{Inclusion Criteria are}

a) Multiparous women.

b) All had regular antenatal check-up since first trimester.

c) All had fetuses of average weight of $(3200 \pm 400) \mathrm{g}$.

d) All term pregnancy.

e) All vertex presentation.

f) All had an ultrasound examination at 38 weeks to assess.

i. Fetal biophysical profile.

ii. Fetal biometry.

iii. Estimated fetal weight.

iv. Study of placenta.

\section{Exclusion Criteria Include}

a) Obstetrical complications like,
i. Preterm Labor.
ii. Premature Rupture of Membranes.
iii. Intrauterine Growth Restrictions.
iv. Malpresentations.
v. Multiple Pregnancy.
vi. Antepartum Hemorrhage.
vii. Previous Caesarean.

b) Instrumental Delivery.

c) Medical Complications Like,

i. Hypertensive disorders of pregnancy.

ii. Diabetes, overt or gestational.

iii. Anaemia.

iv. Systemic diseases.

Right mediolateral episiotomy was done during crowning. Local infiltration by $2 \%$ lignocaine was used as local anaesthesia. All women who underwent and who did not undergo were thoroughly examined immediate postpartum and throughout postpartum for immediate complications and up to six months for late complications.

\section{STATISTICAL ANALYSIS}

Statistical analysis is with the help of SPSS version 11.

Data are analysed by unpaired Student's ' $t$ ' test and $\chi$ square test.

$P$ value $<0.05$ is considered significant.

\section{RESULT}

Total number of cases for study are 500, out of which 250 cases underwent episiotomy and 250 cases did not undergo episiotomy. Mean age of the pregnant women is 23.23 and mean gestational age 40.5 weeks.

\begin{tabular}{|c|c|c|}
\hline Variable & N & Mean \pm SD \\
\hline Age & & $23.23 \pm 2.6$ \\
\hline GA & & $40.5 \pm 1.07$ \\
\hline \multicolumn{2}{|c|}{ Table 1: Age and Gestational Age } \\
\hline
\end{tabular}

GA-Gestational Age

\begin{tabular}{|c|c|}
\hline Parity & Number (n) \\
\hline Para 2 & 132 \\
\hline Para 3 & 103 \\
\hline Para 4 & 15 \\
\hline TOTAL & $\mathbf{2 5 0}$ \\
\hline \multicolumn{2}{|c|}{ Table 2: Parity } \\
\hline
\end{tabular}

\begin{tabular}{|c|c|c|c|}
\hline \multicolumn{2}{|l|}{ Type } & \multicolumn{2}{|c|}{$\begin{array}{c}\text { Mean } \\
\text { Days }\end{array}$} \\
\hline \multicolumn{2}{|c|}{ With episiotomy } & \multicolumn{2}{|c|}{$3.2 \pm .2$} \\
\hline \multicolumn{2}{|c|}{ Without episiotomy } & \multicolumn{2}{|c|}{$2.1 \pm .2$} \\
\hline \multicolumn{4}{|c|}{ Table 3: Hospital Stay } \\
\hline Type & $2^{\circ} \mathrm{PT}$ & $3^{\circ} \mathrm{PT}$ & $4^{\circ} \mathrm{PT}$ \\
\hline Episiotomy & 250 & 23 & 7 \\
\hline Non-episiotomy & 178 & 9 & 4 \\
\hline \multicolumn{4}{|c|}{ Table 4: Complications } \\
\hline
\end{tabular}

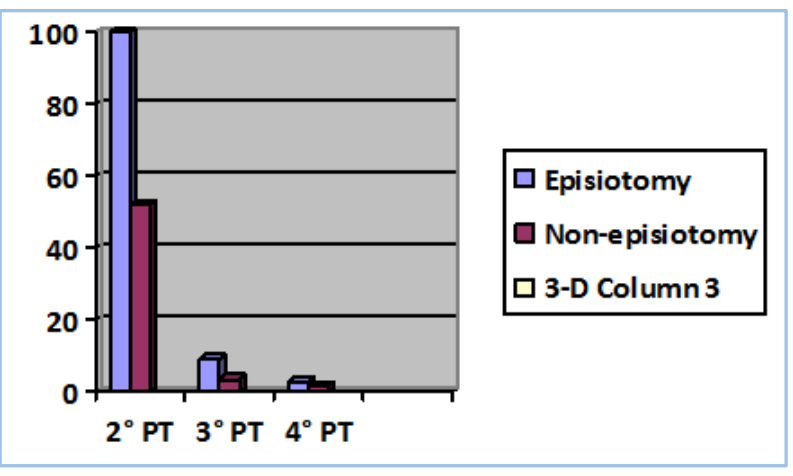

PT-Perineal Tear

Fig. 2: Complications-Percentage

\section{DISCUSSION}

In the US, episiotomy has markedly reduced in the past 35 years. National Hospital Discharge Survey between 1979 and 1997 reveals a reduction of episiotomy from $65 \%$ to $39 \%$ in 1979 and 1997 respectively.[7] In France also, there is marked reduction of routine episiotomy.[8] Contrary to popular belief of reduction of pain and improved healing by episiotomy, some studies are against this. Another advantage of episiotomy that prevents pelvic organ prolapse also has been questioned. ${ }^{[9]}$ Instead of preventing $3^{\circ}$ and $4^{\circ}$ perineal tear, episiotomy is responsible for $3^{\circ}$ and $4^{\circ}$ perineal tear.

Traditionally, physicians have used episiotomies to minimize perineal trauma and postpartum pelvic floor dysfunction. Episiotomy also increases post-partum pain, incontinence and sexual dysfunction.[10] A study by Thacker et al. questions the usefulness of routine episiotomy.[11]

Thacker et al. conducted study on women giving birth between 2005 and 2006 meeting the inclusion criteria, i.e. women at low-risk who expected vaginal delivery at over 38 weeks' gestation with a single fetus in the vertex presentation. One hundred and sixty five women were invited for postpartum check-ups 3 months later and 55 attended.

A detailed gynaecologic examination was carried out and the perineum was carefully inspected by the same physician. Questionnaires were administered and 20-minute face-to-face interviews were carried out to compare the women's sexual lives before pregnancy and after giving birth.

Their conclusions were against the dictum of routine episiotomy. Episiotomy did not decrease postpartum pain.

Compared to women with intact perineum, those who had both episiotomy and second degree perineal tears, had lower levels of libido, orgasm and sexual satisfaction and more pain during intercourse. The presence of at least one sexual problem (Reduced sexual desire, reduced vaginal arousal, reduced vaginal lubrication, reduced frequency of orgasm, dissatisfaction with sexual life and dyspareunia) was statistically significant more common after birth. 
Study by Fritel X reveals a policy of routine episiotomy does not protect against urinary or anal incontinence four years after first delivery.[9]

Study by Chang shows episiotomy increased pain at weeks 1, 2 and 6 postpartum and urinary incontinence at 3 months postpartum.[12] The conclusion is after a prospective follow-up study of 243 women who completed the Taiwanese versions of the Short Form McGill Pain Questionnaire, International Consultation on Incontinence QuestionnaireUrinary Incontinence Short Form, Female Sexual Function Index and a demographic questionnaire after vaginal delivery in a Taiwanese Medical Center.

Review of Cochrane Pregnancy and Childbirth Group trials registry reveals marked reduction in $3^{\circ}$ and $4^{\circ}$ perineal tear and long term complications when episiotomy reduced from $73 \%$ to $28 \%$.[3]

They included eight studies (5541 women). In the routine episiotomy group, $75.15 \%$ (2035/2708) of women had episiotomies, while the rate in the restrictive episiotomy group was $28.40 \%$ (776/2733). Compared with routine use, restrictive episiotomy resulted in less severe perineal trauma (relative risk (RR) $0.67,95 \%$ confidence interval (CI) 0.49 to 0.91), less suturing (RR $0.71,95 \% \mathrm{CI} 0.61$ to 0.81 ) and fewer healing complications (RR $0.69,95 \%$ CI 0.56 to 0.85 ).

Restrictive episiotomy was associated with more anterior perineal trauma (RR 1.84, 95\% CI 1.61 to 2.10). There was no difference in severe vaginal/perineal trauma (RR 0.92, 95\% CI 0.72 to 1.18); dyspareunia (RR 1.02, 95\% CI 0.90 to 1.16 ); urinary incontinence (RR $0.98,95 \% \mathrm{CI} 0.79$ to 1.20 ) or several pain measures. Results for restrictive versus routine mediolateral versus midline episiotomy were similar to the overall comparison.

\section{Authors' Conclusions}

Restrictive episiotomy policies appear to have a number of benefits compared to policies based on routine episiotomy. There is less posterior perineal trauma, less suturing and fewer complications, no difference for most pain measures and severe vaginal or perineal trauma, but there was an increased risk of anterior perineal trauma with restrictive episiotomy.

Present study also supports the above studies. It is evident from the present study conducted during 2010-2014 that there is increased incidence of $3^{\circ}$ and $4^{\circ}$ perineal tear in episiotomised cases. These cases were followed up for 6 months after delivery. There was increased incidence of sexual dysfunction in episiotomised cases. Five cases had stress incontinence in episiotomy cases and only one had in non-episiotomy case. One case of episiotomy had fecal incontinence. It requires further followup for proving the efficacy of episiotomy to prevent prolapsed uterus.

Birth injuries were more or less similar in both study groups. Milestones of development were also normal in both groups.

\section{CONCLUSION}

A prospective study comparing the advantages and disadvantages of routine episiotomy and no episiotomy was conducted. Total number of cases was episiotomy 250 and no episiotomy 250. From the analysis of all data, the following conclusions are arrived.
- Routine episiotomy causes more morbidity to parous women.

- Routine episiotomy causes more $3^{\circ}$ and $4^{\circ}$ perineal tear.

- It does not decrease postpartum perineal pain.

- There is increased incidence of sexual dysfunction in episiotomised cases.

- There is increased incidence of stress incontinence in episiotomised cases.

- Routine episiotomy causes more chance of fecal incontinence.

- Further follow-up is necessary for proving the efficacy of episiotomy to prevent future pelvic organ prolapse.

\section{ACKNOWLEDGMENT}

We express our sincere gratitude to the management of Kannur Medical College, Anjarakandy, for funding the study and ethical committee to grant permission to conduct the present study.

\section{REFERENCES}

1. Kettle C, Hills RK, Ismail KMK. Continuous versus interrupted sutures for repair of episiotomy or second degree tears, Cochrane Database Syst Rev. 2007 Oct 17; (4):CD000947.

2. Ould F: A treatise of midwifery. J Buckland; London: 1741. pp. $145-6$.

3. Carroli G, Mignini L. Episiotomy for vaginal birth. Cochrane Database Syst Rev 2009, Issue 1. Art. No.: CD000081. DOI: 10.1002/14651858.CD000081.pub2.

4. Albers LL, et al. (2006). "Factors related to genital tract trauma in normal spontaneous vaginal births." Birth 33(2):94-100.

5. Fernando R, Sultan AH, Kettle C, et al. Methods of repair for obstetric anal sphincter injury. Cochrane Database Syst Rev 2006;(3) DOI: 10.1002/14651858.

6. Lede 1996. Lede R, Belizan JM, Carroli G: Is routine use of episiotomy justified? Am J Obstet and Gynaecol 1996;174:1399-402. [PubMed: 9065102].

7. Weber AM, Meyn L (2002: Episiotomy use in the United States, 1979-1997, Obstet Gynaecol 100(6):1177-82.

8. Reinbold D, Eboue C, Morello R, et al. From the impact of French guidelines to reduce episiotomy's rate. J Gynaecol Obstet Biol Reprod (Paris). 2012 Feb;41(1):62-8. doi: 10.1016/j.jgyn.2011.08.006. Epub 2011 Oct 20.

9. Fritel X, Schaal JP, Fauconnier A, et al. Pelvic floor disorders four years after first delivery: a comparative study of restrictive versus systematic episiotomy. Gynaecol Obstet Fertil 2008 0ct;36(10):991-7. doi: 10.1016/j.gyobfe.2008.07.009. Epub 2008 Sep 17

10. Ratfisch G, Dikencik BK, Kizilkaya Beji N, et al. Effects of perineal trauma on postpartum sexual function. J Adv Nurs 2010 Dec; 66(12):2640-9. doi: 10.1111/j.13652648.2010.05428.x. Epub 2010 Aug 23.

11. Thacker SB, Banta HD. Benefits and risks of episiotomy: an interpretative review of the English language literature, 1860-1980, Obstet Gynaecol Surv 38(6):32238.

12. Chang SR, Chen KH, Lin HH, et al. Comparison of the effects of episiotomy and no episiotomy on pain, urinary incontinence and sexual function 3 months postpartum: a prospective follow-up study. Int J Nurs Stud 2011 Apr; 48(4):409-18. doi: 10.1016/j.ijnurstu.2010.07.017. 